\title{
Is Spontaneous Resolution of Traumatic Tension Pneumothorax Possible? A Case Report and Brief Review of Literature
}

\author{
Richard M Lynch ${ }^{1}$, Hisham N Osman ${ }^{2}$ and Eltaib A Saad ${ }^{3 *}$ \\ ${ }^{1}$ Consultant in Emergency Medicine, Europe \\ ${ }^{2}$ Registrar in Emergency Medicine, Europe \\ ${ }^{3}$ Senior House-Officer in General Surgery, Midland Regional Hospital Mullingar (MRHM), Europe
}

Received: October 11, 2018; Published: October 31, 2018

*Corresponding author: Eltaib A Saad, MRCS Ed, Senior House-Officer in General Surgery, Midland Regional Hospital Mullingar, Co-Westmeath, Ireland, Europe

\begin{abstract}
Tension pneumothorax is an infrequently encountered clinical condition in the emergency departments. It is a potential life-threatening condition which can result in cardiopulmonary deterioration and ultimately cardiac arrest if not promptly diagnosed and managed. It has various etiologies with blunt chest injuries being one of common causes. We report a rare case of a large traumatic tension pneumothorax following a blunt injury which resolved without specific intervention. The diagnosis was initially missed in the emergency department and was identified on a retrospective radiology report after 2 days. A repeat CXR has surprisingly shown that the tension pneumothorax resolved into "simple" pneumothorax without specific intervention. Interestingly, the patient remained stable all through his hospital stay for 7 days.
\end{abstract}

Conclusion: A spontaneous resolution of a large traumatic tension pneumothorax in a previously healthy and hemodynamically stable patient can occur. Nevertheless, the exact mechanism of this observation still remains poorly understood.

\section{Learning points}

a. The possibility of the tension pneumothorax should be considered in blunt chest trauma patients even when the typical clinical features are not present.

b. A radiologically-diagnosed tension pneumothorax should be promptly managed.

c. An alert system should be activated if critical radiological findings are detected and an effective response has to be followed by the trauma management team

Keywords: Tension pneumothorax; Misdiagnosis; Critical radiological finding; Spontaneous resolution

Abbreviations: ATLS: Advanced Trauma Life Support; CXR: Chest X-Rays; ED: Emergency Department, GCS: Glasgow Coma Scale

\section{Background}

Tension pneumothorax is an infrequently encountered clinical occurrence with a variable incidence worldwide $[1,2]$. It merits special attention as it is a potentially life-threatening condition due to the progressive hemodynamic instability and cardiopulmonary deterioration. A high index of clinical suspicion is therefore required for a prompt diagnosis [1,2]. The recommendations regarding the management of pneumothoraxes depend on size, underlying etiology, and clinical stability of the patient [1]. The Advanced Trauma Life Support (ATLS) guidelines recommend insertion of a chest drain in a patient with a traumatic pneumothorax to prevent developing a tension pneumothorax [3].

We report an unusual case of a large traumatic tension pneumothorax in which the tension pneumothorax resolved spontaneously without specific intervention. The patient was stable all through his hospital stay; his oxygen saturation remained above $94 \%$ when breathing room air. To the best of our knowledge this is only the second reported case in the English medical literature in which spontaneous resolution of a large traumatic tension pneumothorax occurred [1].

\section{Case Presentation}

A previously healthy 23-year-old non-English speaking male was brought to our Emergency Department (ED) four hours earlier following an assault by a group of people. He stated that he had been hit repeatedly by heavy objects on different parts of his body. He complained of severe pain in both arms and right leg. There was no history of loss of consciousness, headache or 
vomiting. He denied chest pain or shortness of breath. His past medical and surgical history was insignificant. He was alert but in severe pain.

His vital signs on arrival were heart rate 102 beats per minute, blood pressure 131/87 $\mathrm{mmHg}$, respiratory rate 22 breaths per minute and an oxygen saturation of $94 \%$ when breathing on room air. His GCS was 15. Multiple superficial abrasions were noted on his forehead and scalp, anterior aspect of the both forearms and the right lower leg. Tenderness was elicited over the right lower leg. Examination of the chest, abdomen and back was reported as normal by the ED resident. Right leg X-ray showed a right distal tibial fracture without deformity. His CXR revealed a large tension left-sided tension pneumothorax (Figure 1).

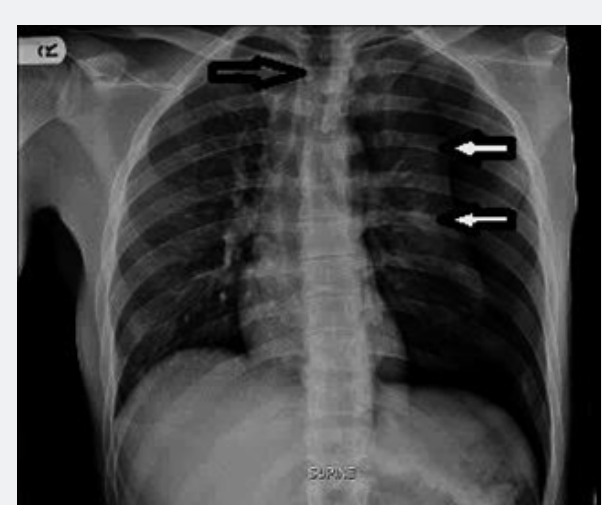

Figure 1: Initial CXR that was obatined in th ED. Left-sided tension pneumothorax (white rrows) with midline shift towards the right side (black arrow).

However, this critical finding was missed by the ED resident and the patient was admitted for neuro-observation and pain management. He remained clinically stable with normal neuroobservations. A retrospective radiology report received 2 days later depicted those findings which were consistent with a leftsided tension pneumothorax. On receipt this radiological report a repeat CXR was taken which revealed a left-sided pneumothorax with no midline mediastinal shift or tension features Figure 2 , thus a spontaneous decompression of the previously noted tension pneumothorax occurred without specific intervention, a finding that was both a clinical as well as a radiological surprise.

The patient remained vitally stable all through his hospital stay and his oxygen saturation was constantly maintained above $94 \%$ when breathing room air. He never complained of shortness of breath or chest pain. Following this repeat CXR, size 32F chest drainage was inserted by the surgical team after informed consent for the "simple" large left-sided pneumothorax. A follow-up CXR showed a satisfactory position of the chest drain. He was reviewed at a Fracture Clinic on Day 5 for further management of the right tibial fracture. The chest drain remained in-situ for 4 days and was removed on Day 6 and the final CXR was relevant for a very small $(<5 \%)$ pneumothorax. He was discharged home on Day 7 in a stable condition. The patient didn't attend scheduled follow-up visits.

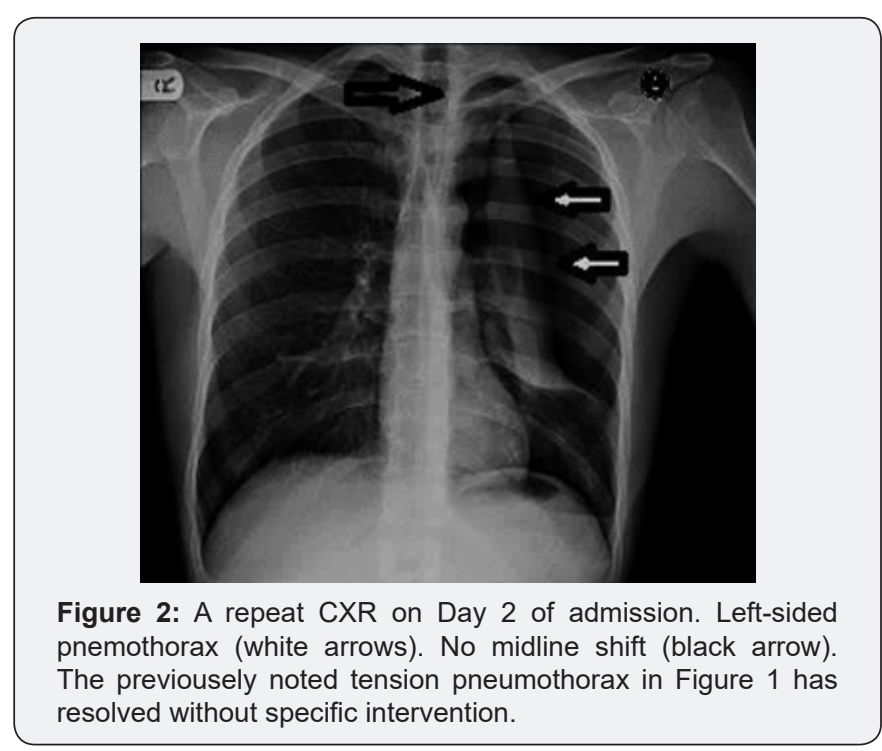

\section{Discussion}

The importance of the prompt clinical diagnosis of tension pneumothorax has been well-emphasized. The clinical features suggesting a tension pneumothorax are chest pain and respiratory distress (90\%), tachycardia and ipsilateral decreased air entry (50-70\%), low oxygen saturation, hypotension and contra-lateral tracheal deviation in less than $25 \%$ [2]. Nevertheless, these typical features are not always present [1,2]. Moreover, these features are poorly correlated with the diagnosis, and perhaps many cases were missed before doing chest radiographs [4]. In fact, there is increasing appreciation that tension pneumothoraces are generally diagnosed radiologically rather than clinically [4]. We have only identified one case of spontaneous resolution of a large traumatic tension pneumothorax in the reviewed English literature [5].

The reported patient was a clinically stable 33-year-old female who presented to ED following a fall. Her CXR showed a large right-sided tension pneumothorax and rib fractures, however, the diagnosis was missed by the ED resident and she was sent home. The diagnosis was made on a retrospective basis after reviewing her CXR and all attempts to contact her had failed. However, she returned to the hospital after 50 days with intractable vomiting due to methadone withdrawal and an admission CXR showed a complete resolution of the previously noted tension pneumothorax [5]. This reported case bears two similarities to ours as the diagnosis was initially missed by the ED doctor and the patient remained clinically stable through the course of the disease. However, we re-evaluated the patient after 2 days and this explains the resolution of tension pneumothorax with persistence of pneumothorax, as the presumed re-absorption rate is $1.25 \%$ per day on room air [6], and hence a complete lung re-expansion will not be expected after 2 days only.

This case demonstrates that tension pneumothorax can be a radiological diagnosis in clinically stable patients, nevertheless it should be managed promptly to prevent grave consequences that 
would rapidly occur. An alert system should be activated if critical radiological findings are detected and an effective response must be followed by trauma management team.

\section{Conclusion}

A spontaneous resolution of a large traumatic tension pneumothorax in a previously healthy and hemodynamically stable patient can occur. Nevertheless, the exact mechanism of this observation remains poorly understood.

\section{References}

1. Yoon JS, Choi SY, Suh JH, Jeong JY, Lee BY, et al. (2013) Tension pneumothorax, is it a really life-threatening condition? J Cardiothorac Surg 8(1): 197.

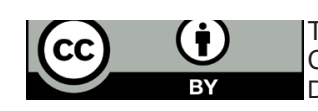

This work is licensed under Creative Commons Attribution 4.0 Licens DOI: 10.19080/OAJS.2018.09.555775
2. Leigh Smith S, Harris T (2005) Tension pneumothorax-time for a rethink? Emerg Med J 22(1): 8-16.

3. ATLS Sub-committee (2013) American College of Surgeons' Committee on Trauma; International ATLS working group. J Trauma Acute Care Surg 74(5): 1363-1366.

4. Holloway VJ, Harris JK (2000) Spontaneous pneumothorax: Is it under tension? Emerg Med J 17(3): 222-223.

5. Ryan MT, Caputo ND, Lakdawala V, Jara F (2012) Spontaneous resolution of a large traumatic pneumothorax. Am J Emerg Med 30(5): 833-e3-5.

6. Kircher LT, Swartzel RL (1954) Spontaneous pneumothorax and its treatment (1954) JAMA 55(1): 24-29.

\section{Your next submission with Juniper Publishers will reach you the below assets}

- Quality Editorial service

- Swift Peer Review

- Reprints availability

- E-prints Service

- Manuscript Podcast for convenient understanding

- Global attainment for your research

- Manuscript accessibility in different formats

(Pdf, E-pub, Full Text, Audio)

- Unceasing customer service

Track the below URL for one-step submission https://juniperpublishers.com/online-submission.php 